\title{
(t)
}

\section{RELAÇÕES SOCIAIS DE SEXO, "RAÇA"/ETNIA E CLASSE: UMA ANÁLISE FEMINISTA-MATERIALISTA}

\author{
SEX, "RACE"/ETHNICITY AND CLASS SOCIAL \\ RELATIONS: A FEMINIST-MATERIALIST ANALYSIS
}

\section{Mirla Cisne ${ }^{1}$}

\section{RESUMO}

O objetivo do nosso artigo é analisar os fundamentos teóricos e políticos da opção pela utilização da categoria relações sociais de sexo consubstanciada com as relações sociais de "raça"/etnia e de classe nos estudos feministas. Para tanto, realizamos uma pesquisa bibliográfica ancorada, especialmente, na produção teórica do feminismo materialista francófono, com destaque para as autoras: Christine Delphy, Jules Falquet, Danièle Kergoat e Anne-Marie Devreux. Esperamos contribuir com o debate teórico que fundamenta o feminismo brasileiro, no intuito de aprofundarmos nossas produções teóricas sintonizadas com as lutas coletivas que nos desafiam cotidianamente na defesa da liberdade.

Palavras-chave: Gênero. Relações sociais de sexo, "raça”/etnia e classe. Feminismo materialista.

\section{ABSTRACT}

The aim of our paper is to analyze the theoretical and political fundamentals of the option to use the category of sex social relations embodied with "race"/ethnicity and class social relations in feminist studies. Thus, we performed a bibliographical research anchored especially in francophone materialist feminism theoretical work, highlighting the authors: Christine Delphy, Jules Falquet, Danièle

1 Professora Adjunta da Faculdade de Serviço Social da Universidade do Estado do Rio Grande do Norte, membro do Núcleo de Estudos Sobre a Mulher Simone de Beauvoir e do Grupo de Estudos sobre as relações patriarcais de gênero e feminismo. E-mail: mirlacisne@gmail.com. 


\section{temporalis}

Kergoat and Anne-Marie Devreux. We hope to contribute to the theoretical debate that moves Brazilian feminism, in order to deepen our theoretical productions tuned with the collective struggles that challenge us daily in defense of freedom.

Keywords: Gender. Sex, "race"/ethnicity and class social relations. Materialist feminism.

Submetido em 24/06/2014

Aceito em 18/09/2014

\section{INTRODUÇÃO}

As discussões de gênero são difundidas fortemente no Brasil a partir da tradução do texto de Joan Scott: "Gênero: uma categoria útil para análise histórica”, realizada pelo SOS Corpo, em 1991, tornando-se um marco referencial para a produção e a atuação política feministas. Desde então, o conceito de gênero e os chamados estudos de gênero passaram a ganhar forte espaço no feminismo brasileiro em detrimento dos chamados anteriormente "estudos feministas" ou mesmo "estudos sobre a mulher". Aqui, surge nossa primeira inquietação com o conceito de gênero: a ocultação do sujeito político mulher que esse conceito, muitas vezes, dilui ou mesmo substitui. Outra forte inquietação é a utilização do conceito de gênero de forma isolada de relações estruturantes do ser social, com destaque para a classe social.

A partir dessas inquietações, passamos a investigar teoricamente a categoria gênero. Nesse processo, encontramos nos fundamentos de grande parte do feminismo materialista francófono a defesa do uso da categoria relações sociais de sexo e não a do conceito de gênero. O objetivo do nosso artigo é analisar os fundamentos teóricos e políticos dessa opção pela utilização da categoria relações sociais de sexo consubstanciada com as relações sociais de "raça"/etnia e classe nos estudos feministas. Para tanto, realizamos uma pesquisa bibliográfica ancorada, especialmente, na produção teórica do feminismo francófono, com destaque para as autoras: Jules Falquet, Danièle Kergoat e AnneMarie Devreux.

Tem sido pauta constante no feminismo a apreensão e elaboração de categorias teóricas que possam contribuir para 
a compreensão crítica da subordinação histórica e das desigualdades que marcam a vida das mulheres, como forma de se instrumentalizar para intervir politicamente para a reversão dessa condição. O movimento feminista, entretanto, possui em seu seio uma diversidade de perspectivas, no que diz respeito tanto à dimensão teórica quanto à política. Por isso, é importante deixar claro que trabalharemos com uma perspectiva marxista do feminismo, orientada para a estratégia socialista e com uma grande aproximação com o chamado feminismo materialista.

Neste artigo, dedicaremos especial atenção para trabalhar categorias e conceitos que dão corpo ao pensamento feminista e ao próprio movimento feminista, no seio da perspectiva acima citada. Ou seja, categorias e conceitos que fundamentam as reflexões e ações do feminismo na luta contra as relações patriarcal ${ }^{2-}$ -racista-capitalistas e em defesa da emancipação humana.

Dentre as categorias e conceitos feministas que trabalharemos, destacamos: a consubstancialidade das relações sociais de sexo, "raça"/etnia e classe.

Esperamos contribuir com o debate teórico que fundamenta o feminismo brasileiro, no intuito de aprofundarmos nossa produção de conhecimentos sintonizada com as lutas coletivas que nos desafiam cotidianamente na defesa da liberdade.

\section{PARA ALÉM DO GÊNERO}

Gênero e relações sociais de sexo são distintos, embora, muitas vezes, encontremos textos que os tratam como sinônimos. Para entendermos o segundo, é fundamental que se localizem a sua origem e o seu significado. Advindo da escola feminista francesa, na língua original é chamado rapports sociaux de sexe. Observemos que na língua francesa esse conceito não é

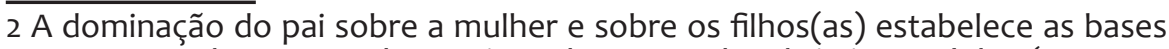
para o que chamamos de patriarcado. Segundo Christine Delphy (2009, p. 174), “'patriarcado' vem da combinação das palavras gregas pater (pai) e arke (origem e comando). [...] Portanto, o patriarcado é literalmente a autoridade do pai". De acordo com Dehphy (2009, p. 173), na acepção feminista, o patriarcado "designa uma formação social em que os homens detêm o poder, ou ainda, mais simplesmente, o poder é dos homens. Ele é, assim, quase sinônimo de ‘dominação masculina' ou de opressão das mulheres". 


\section{temporalis}

denominado relations sociales de sexe. Expliquemos melhor. No francês, existem duas palavras para uma única tradução no português: relações. Rapport designa relações mais amplas, estruturais, enquanto relations diz respeito às relações mais pessoais, individuais, cotidianas. O conceito de rapports sociaux de sexe é diretamente fundamentado no de relações sociais de classe. Uma relação [rapport] social está vinculada aos conflitos e tensões entre os grupos sociais com interesses antagônicos. Portanto, atravessa todo o tecido do campo social e dos fenômenos daí decorrentes. Nas palavras esclarecedoras de Kergoat (2012, p. 126), com base no pensamento de Goldelier (1982): "Uma rapport social é uma relação antagônica entre dois grupos sociais, construída em torno de uma problemática. É uma relação de produção material e ideal" (tradução nossa) ${ }^{3}$.

Ainda para entendermos a diferença entre relations sociales e rapport sociaux, Jules Falquet (2012, p. 138), com base no pensamento de Kergoat (2012), ressalta:

As relações sociais se produzem num nível microssocial, são relações inter-individuais. Elas são relativamente fáceis de modificar, mesmo individualmente. As relações [rapports] sociais surgem de um nível macroestrutural. Elas se articulam entre grupos e só podem ser percebidas ou transformadas indiretamente, coletivamente (tradução nossa) ${ }^{4}$.

Assim, para entendermos o conceito de rapports sociaux de sexe, é necessário compreender a concepção de relação (no sentido de rapport) social a que está associado. Anne-Marie Devreux (2011, p. 7) localiza a categoria rapports sociaux na perspectiva marxista e afirma que é "uma oposição estrutural de duas classes com interesses antagônicos". Nessa mesma perspectiva de compreender o conceito de rapport sociaux no seio do marxismo,

3 Texto original: "Un rapport social est une relation antagonique entre deux groupes sociaux, établie autour d'un enjeu. C'est un rapport de production matérielle et idéelle”.

4 Texto original: “Les relations sociales relèvent d'un niveau micro-social, celui des relations inter-individuelles. Elles sont relativement faciles à modifier, même individuellement. Les rapports sociaux, eux, ressortent d'un niveau macrosocial, structurel. Ils se jouent entre groupes et ne peuvent être perçus ou transformés qu'indirectement, collectivement". 
Annie Bidet-Morel e Jaques Bidet (2010) reafirmam que rapports sociaux não designam as "simples relações entre indivíduos", mas dizem respeito às "relações sociais antagônicas". Ainda segundo os autores, essa perspectiva marxista permite "elucidar a estrutura de classe para compreender a dinâmica histórica" (BIDETMOREL; BIDET, 2010, p. 31, grifos dos autores, tradução nossa5). Aqui cabe uma ressalva: a compreensão da importância da estrutura das classes sociais para o entendimento das relações sociais de sexo não significa que estas se reduzem as primeiras, ou seja, "a relação social de sexo não se reduz ao fato de 'se realizar' dentro das relações sociais de classe" (BIDET-MOREL; BIDET, 2010, p. 41, tradução nossa $\left.{ }^{6}\right)$.

Devreux (2011, p. 10) também nos explica sobre a utilização desse conceito no singular, ou seja, rapport sociale de sexe, que designa uma "síntese teórica das múltiplas dimensões de dominação masculina [...] uma representação científica que traduz a unicidade da lógica da organização do social que constitui essa dominação das mulheres pelos homens e a irredutibilidade dessa dominação a outra relação social".

Outra dimensão importante que merece destaque no conceito de rapports sociaux de sexe é que ele surge no início dos anos 1980, diretamente vinculado e em estreita conexão com os estudos sobre a divisão sexual do trabalho, categoria muito cara para os estudos feministas marxistas. Assim, podemos afirmar que a utilização do conceito de rapports sociaux de sexe, além de sublinhar a dimensão antagônica das classes, assegura o não esquecimento da centralidade do trabalho para os estudos feministas, como defende Kergoat $(2008,2010)$. Já com relação ao conceito de gênero, não podemos afirmar a mesma coisa, tendo em vista que, por vezes, sua utilização é destituída da noção de hierarquia entre os sexos e da de outras desigualdades estruturantes, como as de classe.

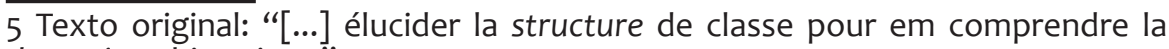
dynamique historique".

6 Texto original: “[...] ler apport social de sexe ne se réduit pas au fait qu'il 'se réalise' dans des rapports sociaux de classe". 


\section{temporalis}

Dessa forma, o conceito de gênero inaugura um outro contexto ou mesmo uma nova conotação teórico-política para o feminismo, bem menos confrontante e mais institucionalizada, como nos explica Falquet (2012, p. 108):

A partir da academia estado-unidense destacadamente, o gênero é introduzido na região principalmente através de teóricos(as) praticantes da cooperação, governamental ou multilateral. Embora muitas vezes usados de forma indiscriminada, muitas vezes, para evitar o estigmatizado termo "feminismo" ou para fornecer um "plus" para a palavra "mulher" - o gênero também introduz uma renovação teórica. Para algumas, ele permite desnaturalizar a opressão das mulheres: no decorrer de milhares de oficinas que foram organizadas no continente para conhecer a teoria do "sistema de sexo-gênero", cada uma aprende que gênero é uma construção social, ainda que se baseie numa diferença biológica (o sexo). Nessas formações aceleradas sobre gênero, a noção de hierarquia entre os sexos é muitas vezes apagada. Quanto às outras relações [rapports] sociais, elas simplesmente desaparecem. Por outro lado, cada vez mais, acrescenta-se a sexualidade, especialmente gay e queer a palavra gênero - a tal ponto que as mulheres quase desaparecem deste discurso para serem substituídas pelas preocupações sobre financiamentos concernentes à discriminação contra gays e trans (destaques da autora, tradução nossa?).

\footnotetext{
7 Texto original: “Issu de l'académie états-unienne notamment, le genre est introduit dans la région principalement à travers les théoricien-ne-s et les pratiquant-e-s de la coopération, gouvernementale ou multilatérale. Quoique souvent utilisé à tort et à travers - souvent pour éviter le terme stigmatisé de « féminisme » ou pour apporter un « plus » au mot « femme »-, le genre introduit aussi un renouveau théorique. Pour certaines, il permet de dénaturaliser l'oppression des femmes : au cours des milliers d'ateliers qui ont été organisés sur le continent pour faire connaître la théorie du "système sexe-genre ", chacune apprend que le genre est une construction sociale,même si elle est basée sur une différence biologique (le sexe). Dans ces formations accélérés sur le genre, la notion de hiérarchie entre les sexes est souvent gommée. Quant aux autres rapports sociaux, ils disparaissent purement et simplement. Par contre, de manière croissante, on accole la sexualité, surtout gay et queer, au mot genre - à tel point que les femmes disparaissent quasiment de ce discours pour être remplacées par des préoccupations et des financements concernant la discrimination contre les hommes gays et trans".
} 
Roland Pfefferkorn (2012) destaca três das principais críticas ou mesmo resistências para a utilização do conceito de gênero. A primeira se refere à "polarização sobre os discursos de uma parte dos pesquisadores de gênero conjugados aos pressupostos culturalistas frequentes nos Estados Unidos" (PFEFFERKORN, 2012, p. 71, tradução nossa ${ }^{8}$ ). Segundo Pfefferkorn (2012, p. 71, tradução nossa ${ }^{9}$ ), essa polarização levou numerosas teóricas a se interessarem pelos "aspectos simbólicos da opressão das mulheres e às representações mais que aos aspectos materiais". A segunda crítica ancora-se no questionamento à distinção entre sexo e gênero, pois, se por um lado o conceito de gênero colaborou para a ruptura com o naturalismo ao enfatizar a construção social das mulheres e dos homens, por outro, contribuiu para a biologização do conceito de sexo, o que leva ao risco de deixar de fora a análise social e histórica dos corpos sexuados. Ou seja, essa dicotomia sexo/gênero pode levar à naturalização do sexo, não o concebendo, também, como construção social e histórica. Por fim, o terceiro aspecto destacado por Pfefferkon (2012) refere-se ao ocultamento da dimensão crítica e conflitual que algumas análises fazem com a utilização do conceito de gênero, como já sinalizamos, também, com Falquet (2012).

Em síntese, os estudos de gênero, se comparados aos estudos feministas, adquirem, por vezes, um caráter mais "neutro", menos ofensivo, ou seja, mais polido ao gosto das instituiçõos multilaterais e governamentais, além de aparentemente mais "acadêmico" ou "científico". Não é à toa, portanto, que os chamados "estudos de gênero" conseguiram uma maior aceitação, penetrando mais facilmente nas "universidades, e mais ainda nas administrações públicas ou nas instituições internacionais" (PFEFFERKON, 2012, p. 79, tradução nossa ${ }^{10}$ ).

Apesar das críticas sistematizadas por Pfefferkorn (2012), com as quais concordamos, o autor defende que gênero é

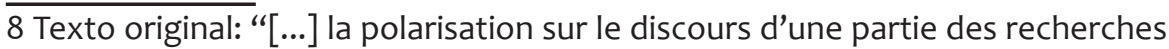
sur le genre conjuguée aux présupposés culturalistes fréquents aux Etats-Unis". 9 Texto original: “[...] aspects symboliques de l'oppression des femmes et aux representations plutôt qu'aux aspectos materials".

10 Texto original: “[...] universités, et davantage encore les administrations publiques ou les institutions internationales". 
um conceito útil, especialmente por permitir unificar as(os) pesquisadoras(es) e o debate sobre as relações entre homens e mulheres, tendo, contudo, a necessidade de conservar sua dimensão crítica. Embora concordemos com o autor e reconheçamos que utilizar gênero não implica, necessariamente, abrir mão de uma perspectiva crítica - haja vista a sua utilização por inúmeras pesquisadoras feministas marxistas, dentre as quais destacamos Saffioti, autora de referência central em nossos estudos -, consideramos mais pertinente a utilização do conceito de "relações [rapports] sociais de sexo". Passemos a qualificar e a aprofundar os fundamentos que nos levam a essa opção teórico-política.

Nos estudos franceses em torno da apropriação ${ }^{11}$ sobre as mulheres, segundo Anne-Marie Devreux (2011), a preferência da adoção da utilização do conceito de "relações sociais de sexo" ao conceito de gênero se dá por várias razões, dentre as quais, destaca: a acentuação do fato de que as relações entre homens e mulheres constituem uma relação social enquanto o gênero diz mais da categorização do sexo, que, para a autora, é um dos

11 Sobre a categoria apropriação, Falquet (2012, p. 168-169) nos esclarece: "Guillaumin [...] explica muito claramente que as relações de classe social, organizadas em torno da exploração, se situam em um plano material diferente das relações de sexo e de 'raça', organizadas em torno da apropriação. A apropriação afeta a pessoa como um todo, corpo e 'alma' sem medida, enquanto que a exploração afeta somente a força de trabalho, mensurada por peça ou em horas. Guillaumin igualmente relatou que existiam dinâmicas históricas de transformação da apropriação para a exploração. Em particular, segundo ela, a capacidade de recuperar uma parte de sua força de trabalho para vendê-la no mercado, graças ao enfraquecimento da apropriação individual (tanto nas relações de escravidão como de sexagem) permite escapar em parte da apropriação (sobretudo individual, ressalta-se mais uma vez). É igualmente o que analisaram Juteau e Laurin ao afirmarem que o assalariamento feminino foi organizado pela apropriação coletiva" (tradução nossa). Texto original: "Guillaumin [...] explique très clairement que les rapports de classe sociale, organisés autour de l'exploitation, se situent sur un plan matériel différent des rapports de sexe et de "race ", organisés autour de l'appropriation. L'appropriation concerne l'ensemble de la personne, corps et " âme ", sans mesure, tandis que l'exploitation ne concerne que la force de travail, mesurée à la pièce ou en heures. Guillaumin a également signalé qu'il existait des dynamiques historiques de transformation de l'appropriation vers l'exploitation. En particulier, selon elle, la possibilité de récupérer une partie de sa force de travail pour la vendre sur le marché, grâce à l'affaiblissement de l'appropriation individuelle notamment (tant dans les rapports esclavagistes que dans le sexage), permet d'échapper en partie à l'appropriation (surtout individuelle une fois encore). C'est également ce qu'ont analysé Juteau et Laurin en affirmant que le salariat féminin était organisé par l'appropriation collective. 
resultados da relação, mas não de toda a relação; relações sociais de sexo nomeiam explicitamente os sujeitos, enquanto gênero evita mencioná-lo e o eufemiza. Além disso, em francês (como no português), gênero é uma palavra polissêmica, o que leva a uma definição vaga ou incerta do conceito. Na avaliação da autora:

[...] a utilização do conceito de "gênero" permitiu às pesquisadoras francesas serem percebidas como menos agressivas, menos "feministas" por suas instituições e seus colegas. Não chocando, elas pensavam chegar mais facilmente a um consenso científico sobre a questão da dominação masculina, mantendo-se mais politicamente corretas. De certa maneira, elas eram mais "polidas", não nomeando nem a violência e o antagonismo contidos na ideia de "relação social", nem o critério um pouco animal de "sexo". É o que também permitiu [...] que pesquisadores homens ingressassem nessa área de pesquisa científica, tornada, assim, mais consensual. [...] o termo "gênero" evoca a ideia de um problema social sofrido pelas mulheres, de uma desigualdade social construída, mas na qual os homens não seriam atores. [...] A relação social de sexo nomeia explicitamente a confrontação entre duas classes de sexo. [...] Não pode haver relação social sem confrontação (DEVREUX, 2011, p. 9).

Nessa mesma linha analítica, ressalta Saffioti (2004, p. 138, destaque nosso): "Gênero é um conceito por demais palatável, porque é excessivamente geral, a-histórico, apolítico e pretensamente neutro. Exatamente em função de sua generalidade excessiva, apresenta grande grau de extensão, mas baixo nível de compreensão". Mediante essa análise de Saffioti, podemos acrescentar um outro elemento crítico ao conceito de gênero. Além de polissêmico, mais palatável, ou pretensamente neutro e de não nomear explicitamente os sujeitos das relações sociais de sexo, o conceito de gênero tem "baixo nível de compreensão" fora dos contextos do que se convencionou chamar de "feminismo acadêmico"12. Em particular no campo da ação política,

12 Os "estudos de gênero" foram fortemente desenvolvidos dentro de instituições universitárias, ou seja, no espaço acadêmico, sem, muitas vezes, estarem associados à luta política do movimento feminista. Daí a expressão "feminismo acadêmico". 


\section{temporalis}

também percebemos que o conceito, dado o seu nível de abstração, dificulta a assimilação e compreensão por parte das mulheres que não possuem formação acadêmica, ainda que sejam os sujeitos centrais do feminismo, já que são elas que estão sujeitas as mais variadas formas de opressão e exploração. Em outras palavras, para nós, o conceito de gênero dificulta a aproximação com quem deve ser o sujeito prioritário do feminismo: as mulheres trabalhadoras. Bem mais fácil e direta torna-se a compreensão por parte dessas mulheres quando falamos em opressão/ exploração das mulheres ou desigualdade entre os sexos, enfim, quando qualificamos, nomeamos e identificamos os sujeitos das "relações sociais de sexo", diferentemente de quando nos referimos à opressão de gênero que, para alcançar o entendimento, primeiro, há de se explicar o próprio conceito de gênero, já que ele não é autoexplicativo, não somente pelo academicismo que o funda, mas, também, pela sua polissemia.

Concordamos com Bandeira (2000, p. 37-38) ao afirmar que "gênero é uma palavra que não tem maior consequência quando empregada separadamente da palavra mulher". Com o advento do conceito de gênero, a categoria mulher, de acordo com Piscitelli (2002, p. 7), "passou a ser quase execrada por uma geração para a qual o binômio feminismo/'mulher' parece ter se tornado símbolo de enfoques ultrapassados". Por essas razões e críticas acima expostas, optamos pela utilização prioritária da categoria "relações sociais de sexo".

\section{A CONSUBSTANCIALIDADE DAS RELAÇÕES SOCIAIS DE SEXO, “RAÇA”/ETNIA E CLASSE}

O conceito francês de "relações sociais de sexo", que entende tais relações como rapports, ou seja, as que dizem respeito às relações sociais mais amplas, permeadas pelos conflitos e antagonismos de classe, facilita-nos a fundamentação do nosso posicionamento teórico-político de que é impensável estudar as relações sociais entre os sexos dissociadas das dimensões de "raça"/etnia e de classe. Para sermos mais claras, partimos do pressuposto de que classe, "raça" e relações sociais de sexo (incluindo a sexualidade) não compõem apenas relações superpostas, tampouco adicionais ou mesmo com "intersecções", 
como defende Crenshaw (1995), entre as relações de "gênero" e "raça". Ao considerar, por exemplo, que elas seriam relações adicionais, ou seja, somáveis, cairíamos na segmentação positivista de entendê-las como relações separadas e não enoveladas, como nos propõe Saffioti (2004, p. 125):

O importante é analisar estas contradições na condição de fundidas e enoveladas ou enlaçadas em um nó. [...] Não que cada uma destas condições atue livre e isoladamente. No nó, elas passam a apresentar uma dinâmica especial, própria do nó. Ou seja, a dinâmica de cada uma condiciona-se à nova realidade. De acordo com as circunstâncias históricas, cada uma das contradições integrantes do nó adquire relevos distintos. E esta motilidade é importante reter, a fim de não se tomar nada como fixo, aí inclusa a organização social destas subestruturas na estrutura global, ou seja, destas contradições no seio da nova realidade - novelo patriarcado-racismo-capitalismo - historicamente constituída.

Seguindo essa linha do pensamento de Saffioti, defendemos que as relações sociais de sexo, "raça"/etnia e classe são "consubstanciais" e "coextensivas" (KERGOAT, 2008, 2010, 2012), tendo em vista que "a força de trabalho que se vende é indissociável do corpo que a porta, e as suas formas de apropriação e exploração estão definidas não só pelas relações de classe como também de 'raça' e de gênero" (ÁVILA, 2011, p. 65).

Sobre a consubstancialidade e coextensividade das relações (rapports) sociais, explica-nos Kergoat (2012, p. 126-127): "As relações sociais são consubstanciais: elas formam um nó que não pode ser sequenciado ao nível das práticas sociais, apenas em uma perspectiva analítica da sociologia; e elas são coextensivas: implantando as relações sociais de classe, de gênero e de 'raça', se reproduzem e se coproduzem mutuamente" (tradução nossa' ${ }^{13}$.

13 Texto original: "Les rapports sociaux sont consubstantiels: ils forment un noeud qui ne peut être séquencé au niveau des pratiques sociales, sinon dans une perspective de sociologie analytique; et ils sont coextensifs : en se déployant, les rapports sociaux de classe, de genre, de « race », se reproduisent et se co-produisent mutuellement". 


\section{temporalis}

Nesse sentido, acreditamos ser "indispensável integrar plenamente em nossas análises os efeitos conjugados de várias relações sociais de poder: de sexo (incluso sexualidade), de classe e de 'raça"' (FALQUET, 2008, p. 122). Para tanto, é fundamental considerar "sobretudo as interpretações das feministas racializadas e/ou proletárias e/ou lésbicas que devem, a meu ver, ser ouvidas e estudadas, se desejarmos produzir uma teoria e uma prática úteis à transformação social radical mais do que nunca necessária” (FALQUET, 2008, p. 122).

As "relações sociais de sexo" e de "raça"/etnia são elementos indispensáveis para entendermos a exploração do mundo do trabalho, especialmente, no que Falquet $(2008,2012)$ denomina de "trabalho desvalorizado" ou "trabalho considerado feminino". Falquet (2012, p. 163) os explica: “[...] as mulheres efetuam sempre majoritariamente 'trabalho de mulheres' com condições de trabalho de mulheres (informalidade, precarização, abuso de todos os tipos, incluindo o assédio sexual e o plafond de verre $e^{14}$ ) e os salários das mulheres” (FALQUET, 2012, p. 163, tradução nossa ${ }^{15}$ ). O "trabalho desvalorizado" e o "trabalho considerado feminino" são entendidos, ainda, como tudo o que se encontra entre a extração de trabalho mediante salário e a extração de trabalhos gratuitos. Essas extrações são “coconstruídas” (FALQUET, 2008). Falquet (2012, p. 170) nos explica:

[...] Em termos de classe e das relações de exploração, o "trabalho desvalorizado" ou "trabalho considerado feminino", tipo de trabalho proletário que não teria atingido o estágio de desenvolvimento completo, permite fazer uma relação entre sexo e classe por um lado, entre "raça" e classe por outro.

14 A tradução literal de plafond de verre para o português seria "teto de vidro". Como cremos que essa expressão não traduz o sentido da frase, preferimos manter o a expressão em francês e explicar o seu sentido. Plafond de verre foi uma expressão cunhada nos Estados Unidos no final dos anos 1970. Em inglês, é chamada glass ceiling e diz respeito a uma estrutura hierárquica, na qual os níveis superiores não são acessíveis a determinadas categorias de pessoas. Em outras palavras, ainda que essa expressão seja designada para outras categorias, ela também assinala a dificuldade de acesso das mulheres aos cargos superiores.

15 Texto original: "[...] les femmes effectuent toujours majoritairement des 'travaux de femmes' avec des conditions de travail de femmes (informalité, précarité, mauvais traitements de toutes sortes incluant le harcèlement sexuel et le plafond de verre) et des salaires de femmes". 
Na verdade, este trabalho desvalorizado obriga que a mão de obra desfavorecida se deixe apropriar precisamente para completar o salário muito baixo obtido por meio da exploração. É em torno desse trabalho desvalorizado que se desenvolve a rearticulação neoliberal das relações sociais, no que eu proponho chamar de uma lógica de vasos comunicantes (grifo da autora, tradução nossa) ${ }^{16}$.

A análise das relações [rapports] sociais de classe, "raça"/ etnia e sexo como "vasos comunicantes" na atual conjuntura de mundialização do capital permite-nos, conforme Falquet (2012), apreender as mudanças dos diferentes e incessantes modos de obtenção do trabalho, uma vez que

as relações de sexo e de "raça", todas duas organizadas em torno da apropriação, se reforçam ou se enfraquecem à medida que a apropriação evolui para a exploração, isto é, para as relações de classe, e simultaneamente como evolui a apropriação individual para a relação de apropriação coletiva. Essa afirmação tem pelo menos quatro consequências fundamentais. (1) Nenhuma das três relações jamais desaparece completamente. (2) Mesmo se pensarmos que podemos mudar uma de cada vez, sua transformação, inevitavelmente impactaria sobre as outras. (3) Todas as transformações são reversíveis [...]. (4) Uma das questões centrais é saber se é um jogo de soma zero ou não: a quantidade total (e a qualidade) de trabalho obtido, seja por exploração, seja por apropriação, é constante? Esta questão, obviamente, depende, entre outras, da escala de tempo a ser considerada (FALQUET, 2012, p. 17, tradução nossa $\left.{ }^{17}\right)$.

16 Texto original: "[...] sur le plan de la classe et des rapports d'exploitation, le «travail dévalorisé» ou "travail considéré comme féminin», sorte de travail prolétaire qui ne serait pas parvenu à son stade de plein développement, permet de faire le lien entre sexe et classe d'une part, entre «race» et classe, de l'autre. En effet, ce travail dévalorisé oblige la main-d'oeuvre défavorisée à se laisser approprier par ailleurs pour compléter le salaire trop faible obtenu dans le cadre de l'exploitation. C'est autour de ce travail dévalorisé que se joue la réarticulation néolibérale des rapports sociaux, dans ce que je propose d'appeler une logique de vases communicants".

17 Texto original: "Les rapports de sexe et de « race ", tous deux organizes autour de l'appropriation, se renforcent ou s'affaiblissent à mesure que l'appropriation 


\section{temporalis}

Assim, por meio das apropriações advindas das relações de "raça"/etnia e sexo, o capitalismo amplia um grande contingente humano disponível para os mais baixos salários, aumentando, portanto, a sua capacidade de exploração do trabalho associada a essas apropriações. Para o desvelamento crítico dessas apropriações, consideramos que as categorias família e divisão sexual do trabalho nos são indispensáveis.

\section{CONCLUSÕES}

Cremos que o conceito de gênero dificulta a compreensão da problemática que envolve as relações sociais de sexo, a começar pela ocultação que muitas vezes promove ao sujeito político mulher, especialmente quando não é utilizado de forma associada ao patriarcado e/ou à categoria mulher, a qual foi substituída em grande medida pelos "estudos de gênero". Isso provoca um sério problema político em termos de desdobramentos para o feminismo, afinal, não podemos, em nenhuma situação, ocultar o seu sujeito político central: a mulher, sem o qual o movimento feminista perde o seu sentido e dilui o seu propósito. Consideramos, portanto, que o conteúdo do conceito de gênero, se apartado das relações sociais de classe e "raça"/etnia e da luta pela erradicação das explorações e opressões daí decorrentes, pouco oferece como "arma da crítica".

Assim, optamos teoricamente pela utilização prioritária do termo "relações sociais de sexo", já que, diferentemente de gênero, ele não deixa dúvida no que diz respeito ao seu vínculo com a ideia de antagonismo social correspondente as relações de exploração e dominação. A utilização do conceito de gênero demanda sempre a demarcação teórica, uma vez que é adotado por diversas perspectivas do pensamento feminista, incluindo

évolue vers l'exploitation, c'est-à-dire les rapports de classe, et simultanément selon comment évolue l'appropriation individuelle par rapport à l'appropriation collective. Cette affirmation possède au moins quatre conséquences fondamentales. (1) Aucun des trois rapport ne disparaît jamais totalement. (2) Même si l'on pense pouvoir n'en modifier qu'un seul à la fois, sa transformation a forcément des retombées sur les autres. (3) Toutes les transformations sont reversible [...]. (4) Une des questions centrales est s'il s'agit d'un jeu à somme nulle ou non: la quantité totale (et la qualité) de travail obtenue, soit par exploitation, soit par appropriation, est-elle constante? Cette question dépend évidemment, entre autres, de l'échelle de temps qui est considérée". 
feministas marxistas e pós-modernas. Além disso, cremos que o conceito de gênero tende à eufemização das relações de poder e do antagonismo social, dada a sua ancoragem no culturalismo.

A categoria relações sociais (rapports) de sexo nos ajuda a compreender que as relações de sexo não são questões isoladas ou meramente individualizadas entre homens e mulheres, mas relações sociais estruturantes, consubstanciadas com os conflitos de classe e "raça"/etnia. Como relações estruturantes, as respostas para alterá-las somente podem ser coletivas, posto que as mudanças nas relações individuais/pessoais, a despeito de sua importância, não alteram em nível estrutural as relações sociais. Tal fato exige a organização de sujeitos políticos coletivos, capazes de dar respostas que incidam em transformações nas relações materiais e ideológicas que organizam a produção e reprodução da vida social.

Referimo-nos aqui à importância dos movimentos sociais e partidos políticos de esquerda que incorporem a luta feminista, antirracista e anticapitalista para a construção de um projeto societário radicalmente pautado na liberdade e na igualdade substantivas. Em outras palavras, cremos na relevância dos sujeitos coletivos em torno de uma luta classista, ou seja, centralizados por um projeto de classe, que é o ponto comum entre todas as lutas que buscam o fim das desigualdades sociais. Todavia, tal projeto deve, necessariamente, incorporar a luta feminista e antirracista para que possamos pensar em uma sociedade livre de todas as formas de opressão e exploração.

\section{REFERÊNCIAS}

ÁVILA, Maria Betânia. As mulheres no mundo do trabalho e a relação corpo e sujeito. Cadernos de Crítica Feminista, n. 4, ano V, p. 48-71, dez. 2011.

BANDEIRA, Lourdes Maria. Feminismo: memória e história. In: SALES, Celecina; AMARAL, Célia; ESMERALDO, Gema. Feminismo: memória e história. Fortaleza: Imprensa Universitária, 2000. p. $15-41$. 


\section{temporalis}

BIDET-MOREL, Annie; BIDET, Jaques. Les rapports de sexe comme rapports sociaux suivi de Rapports sociaux de sexe e rapports sociaux de classe. In: BIDET-MORDREL (Org.). Les rapports sociaux de sexe. Atual Marx Confrontation. Paris: Presses Universitaires de Frances, Deuxième semestre, 2010. p. 15-43.

CRENSHAW, Kimberle. The Intersection of Race and Gender. In: CRENSHAW, Kimberle; GOTANDA, Neil; PELLER, Garry; THOMAS; Kendal (Ed.). Critical Race Theory: the Key Writings That Formed the Movement. New York: New Press, 1995. Law Review, n. 65. p. 1467-76.

DELPHY, Christine. Patriarcado. In: HIRATA, Helena et al. (Org.). Dicionário Crítico do Feminismo. São Paulo: Editora da UNESP, 2009. p. 173-178.

DEVREUX, Anne-Marie. A teoria das relações sociais de sexo: um quadro de análise sobre a dominação masculina. Cadernos de Crítica Feminista, n. 4, ano V, p. 6-28, dez. 2011.

ELSON, Diane. Commerce Internacional, Égalité des sexes et avantage compétitif. In: FALQUET Jules; HIRATA, Helena; KERGOAT, Danièle. Le sexe de la mondialisation. Paris: Presses de Sciences Po, 2010. p. 57-70.

FALQUET, Jules. Repensar as relações sociais de sexo, classe e " "raça”" na globalização neoliberal. Mediações, Londrina, v. 13, n. 1-2, p. 121-142, jan./jun. - jul./dez. 2008.

. Les mouvements sociaux dans la modialisation néolibérale: imbrication des rapports sociaux et classe des femmes (Amérique latine-Caraïbes-France). Habilitation à diriger des recherches (mimeo). Paris: Université de Paris 8, 2012.

KERGOAT, Danièle. Dynamique et consubstantialité des rapports sociaux. In: DORLIN, Elsa (Org.). Sexe, classe, race: pour une épistémologie de la domination. Paris: Editora da PUF, 2008. p. 111-125.

- Dinâmica e consubstancialidade das relações sociais. Novos Estudos, n. 86, p. 93-103, mar. 2010. 
. Se battre, disent-elles... Paris: La Dispute, 2012.

PFEFFERKORN, Roland. Genre et rapports sociaux de sexe. Paris: Page deux, 2012.

PISCITELLI, Adriana. Recriando a (categoria) mulher? In: ALGRANTI (Org.). A Prática Feminista e o Conceito de Gênero. São Paulo: IFCH/Unicamp, 2002. p. 7-42. Textos Didáticos.

SAFFIOTI, Heleieth. Gênero, patriarcado, violência. São Paulo: Perseu Abramo, 2004.

SCOTT, Joan. Gênero: uma categoria útil para análise histórica. Recife: SOS Corpo, 1991. 